\title{
Assessing the Implementation of Biophilic Design Strategies in Selected office Buildings in Lagos State, Nigeria
}

\author{
E.B. Aduwo, 0.0. Akinwole
}

\begin{abstract}
With the ever-increasing rate of urbanization and organisations opting to discard biophilic designs for minimalist designs at the detriment of productivity, the natural environment has been cast-off as a critical feature in determining the quality of human life. It has been discovered that there is an innate desire for human beings to connect with nature, which is being described as biophilia. Thus, organisations are seeking innovative measures of integrating the natural environment into the workplace as it has been proven to enhance well-being and productivity while saving cost. The study area, Lagos state is a densely populated city whose rise in population has been poorly managed with increasing pollution levels that reduce the quality of life, which is why it is imperative for organisations to create a sustainable environment that enhances work activities. To this end, this study seeks to evaluate the implementation of biophilic design strategies in selected office buildings in Lagos, Nigeria. Data is obtained using questionnaires and analysed using both content analysis for qualitative data and descriptive statistics for quantitative data. Purposive sampling was used to select the buildings that were studied while the respondents were selected by means of the stratified sampling technique. The findings reveal that daylight is the most implemented biophilic design strategy. The benefits of biophilic integration have been reviewed, as well as areas for future research. With more attention being placed on conducive workplace environment this research helps to ascertain the most utilized biophilic design strategy and how it can be easily incorporated in buildings.
\end{abstract}

Keywords: Biophilia, Biophilic design, Office, Productivity

Biophilia is the innate human tendency to connect with natural systems and processes, particularly living features of the nonhuman environment [1].

Human's inclination to interact with nature reflects the certainty of having developed into a largely natural world as to a non-natural or constructed one [1], [2]. Over the years, we as human beings have progressed for larger parts of our history in adaptive response to the natural environment and

Revised Manuscript Received on May 15, 2020.

* Correspondence Author

O.O. Akinwole *, Architecture, Covenant University, Ota, Nigeria. E-mail: olamideakinwole@gmail.com

E.B. Aduwo, Architecture, Covenant University, Ota, Nigeria.

E-mail: egidario.aduwo@covenantuniversity.edu.ng

(C) The Authors. Published by Blue Eyes Intelligence Engineering and Sciences Publication (BEIESP). This is an open access article under the CC BY-NC-ND license (http://creativecommons.org/licenses/by-nc-nd/4.0/)

\section{INTRODUCTION}

not to the built or artificial environment. The postulation that human evolution and civilization is independent of nature is a very misleading illusion [3].

Our constructive abilities, critical thinking, and problem solving continue to imitate skills and attributes attained in close association with natural systems and processes that remain critical in human health and productivity. We must understand that contact with nature is a necessity rather than a luxury for attaining lives of wellness and satisfaction [4].

\section{LITERATURE REVIEW}

Over the years, as technology advanced, the design of the modern built environment brought about a significant transformation and degradation of the natural environment, as well as a growing human separation from the natural ecosystem. This is a dilemma, we designed ourselves into, and can literally design ourselves out of, but would require engaging in a new course of action that pursues "reconciliation if not harmonization with nature" [2].

\section{A. Restorative Environmental Design}

This new paradigm shift is dubbed "restorative environmental design". This is a ploy that seeks to achieve a low-environmental-impact-approach that restrains and moderate adverse effects on the natural environment and at the same time attain a positive environmental influence that creates an opportunity for valuable interaction between people and nature in contemporary buildings and landscapes [4].

The green design approach started after the realisation of the adverse effects, that the modern built environment had imposed on the natural environment. Measures were put in place to mitigate these effects but were deemed ultimately inadequate, largely disregarding the significance of attaining lasting sustainability by fostering a human connection with nature in the built environment. Sustainability, as distinguished by the Brundtland Commission (1987), (which was formerly known as The World Commission on Environment and Development) is satisfying the needs of the current generation without conceding the ability of imminent generations to take care of their own desires, but this is dependent on the circumstance that people remain interested in the structure/space in question and develop a sense of attachment to that structure/space.

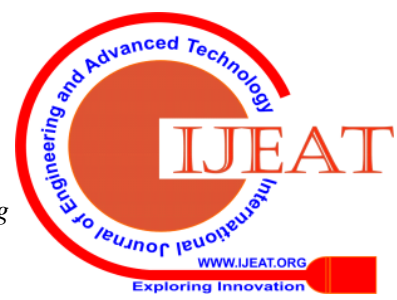


Pioneering low environmental impact technology would always be relevant for a while until it isn't and becomes outdated when this happens people turn to erect new structures that serve their needs. "Sustainability is as much about keeping buildings in existence as it is about constructing new low-impact efficient designs" [2].

\section{B. Biophilic Design}

This is simply put as the integration of natural elements into the design of spaces. "Biophilic design is more than just bringing the outside in. It is about making and strengthening a connection with many aspects of nature. It is about natural light, views on nature, plants, natural materials, textures and patterns" [6]. Designs that do not emphasize on facets of the natural world that add value to human health and productivity in the life-long brawl to be fit and survive are simply not biophilic [1].A distinctive feature of biophilic design is its emphasis on the integration or sum of its parts, that is the overall setting rather than a single or isolated occurrence of nature. A widely accepted biophilic design is regarded as one that considers several significant points of view such as; socio-cultural standards and prospects, wellbeing, past involvements, frequency and extent of the user experience, as well as the discernment of the users in processing the experience - to produce inspiring, habitable, soothing spaces that can be integrated with the functionality of the place and urban environment to which it is applied. Most importantly, the biophilic design must foster an affection of place [7].

With the development of new ideas and concepts, which has led to differing views on what good biophilic design is defined as, there is hardly a solution that meets all the criteria. Rather, the 'appropriate' solution, is one that is locally suitable and responsive to the situation at hand.

\section{Biophilic Architecture and Sustainable Architecture}

Biophilic architecture is a new concept in architecture which places human beings at the core of its concepts, as well as their complementing relationship with nature in the built environment. Biophilic design has gained more attention due to the global phenomenon of climate change and high rate of urbanisation which has made it less easy for human beings to connect with nature. Biophilic architecture has sustainable benefits and it can be said that biophilic architecture is an extension of sustainable architecture [8]. Furthermore, they highlighted the potential of structures to increase our awareness of nature by the availability of natural elements that promote sustainability schemes intentionally or unintentionally.

Green features like green roofs, courtyards, planters which are key biophilic design strategies are also elements of passive sustainable strategies. Therefore, biophilic and sustainable architecture share the same strategies as the basis of their influence.

Sustainable design places emphasis on the environmental impact of buildings while biophilic design, in addition, focuses on the social effect of buildings by incorporating elements nature into the built environment to improve wellbeing among people. Hence, biophilic design is said to be an extension of sustainable design because a fundamental change in underlying assumptions of designing the built environment from just a mere consideration of the environmental impact of buildings (sustainability's mantra) to rational thinking and understanding how the built environment affects occupants' wellbeing has been attained. [9]. In conclusion biophilic design employs a strategy of connecting humans with nature and sustainable principles [10]. In 2015, Fenner and Elser described biophilic architecture as simply taking into account the human factor in sustainable design [11].

\section{Economic Advantages of Biophilia in the Workplace}

The workplace is the crux of progress in modern society and it has been revealed that there is a potentially relevant business case to be made in integrating biophilic design into office spaces. Absenteeism simply means the rate of how frequent workers are not available for work, while presenteeism is a measure of how often employees are physically present but not at their best in terms of performance as a result of weariness, ailment, lack of motivation or an impaired mood. A level of absenteeism in the workplace can be tolerated, researchers have made informed assumptions that a substantial amount of prevailing absenteeism rates can be avoided through biophilic interventions in the workplace. However, it is imperative to take into consideration that in most of the literature reviewed on biophilic design, there is a reasonable amount of ambiguity that surrounds the true economic paybacks of putting into effect design strategies that focus on improving employee productivity. This is as a result of the fact that productivity benefits cannot be quantified easily as opposed to cost reduction strategies [12].

Return-on-investment (ROI) is easy to calculate for upgrades in facilities like energy efficiency where hard data is easily quantified from monthly energy bills, which is not the case with worker productivity.

In any design linked process, the cost of implementing certain biophilic strategies could literally be nothing, if they are integrated from the onset and not as an after-thought. The section to follow of this report will present a study which has begun to build an economic case for the use of biophilic design in the workplace.

\section{E. History of Office Design}

Over the years, the spaces we live in have evolved, as well as the way we approach a work setting design. What began as a trial experiment, on gathering information on how to attain maximum efficiency from an organisation to its employees has developed into a more disciplined course - one that draws attention to people [13].

The evolution is summarised as follows:

\section{- 1900s: The innovation of steel}

During a period of 'economic efficiency' where offices were set-up in a linear arrangement, the meek steel girder paved the way for what we now recognise as the modern open plan. This alloy of metals permitted for the opening up of large internal spaces.
Blue Eyes Intelligence Engineering

\& Sciences Publication

(C) Convriaht: All riahts reserved

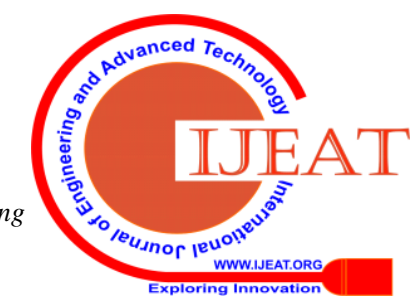




\section{- 1960s: The birth of office landscapes}

In a time where the workplace environment was characterised with bureaucracy. The challenge was to adopt a socially representative design, that fostered interaction among people.

- 1980s: Outside the box but still in a box

After the era of office landscapes, the development towards biophilic design and office space enlightenment would have been thought as the next step. There were some hindrances however, such as the prevalent cubicle system that characterised this period. With the emergence of organic and open floor plans, several organisations responded to this new approach by trying to attain a level of privacy on the office floor. The cubicle was adopted across many business models as a way to achieve discretion within the exposure.

\section{- 2000s: The millennial era of flexibility}

The new millennium brought along the idea that; we might not have to be present in the office to work. The advancement in wireless technology and coffee shops has helped release employees from their cubicles. The objective was to give the office a different appeal where work and recreation could co-exist in the same space.

- 2010s: Advent of biophilia and a sense of community

Organisations and their employees recognised that there is more to an office design than just recreational spaces. Contemporary workplaces communicate their ideas easily, inspiring a feeling of community, and finding solutions to problems together. Biophilic design is the element that links all these together. Integrating natural elements in the workplace is on the increase from remarkable vertical gardens in Singapore to green environment at renowned organisations like Apple and Google, the benefits are now being appreciated globally. Increased productivity is now associated with environments that are linked with nature and promote interaction.

\section{METHODOLOGY}

For this research, the research design includes both the quantitative and qualitative strategy of inquiry which involved the use of structured questionnaires to users and a critical observation guide to analyze the buildings selected.

\section{A. Sampling method}

Sampling consists of a process of sub-selecting a population that represents the entire population and there are two major methods namely, probability sampling and non-probability sampling methods. The probability method yields probability samples where there is assurance that each respondent can be selected, thereby leaving no room for the existence of bias. It can be further classified into simple random sampling and stratified sampling. The non-probability method contains bias and there is no assurance that all respondents will be selected.

The purposive sampling method of the non-probability method was adopted for the qualitative data that deals with the selection of high-rise office buildings. This method was used in order to assess all categories of high-rise buildings relevant to the scope of the study. The selection of respondents for quantitative data was done by stratified sampling because the population in these offices is heterogeneous.

\section{B. Sample size}

The sample size technique is to help determine the number of observations to include in a sample. The determination depends on five study parameters: the effect size, estimated measurement variability, desired statistical power and a significance criterion, all of which will help determine an appropriate sample size with a level of precision of $+5 \%$, a confidence level of $95 \%$

The sample size to be studied is four high-rise office buildings based on researcher's selection. This will involve a purposive sampling of eight high-rise office buildings on the availability of the facilities that are required in the study. The buildings are as shown in the table below;

Table- I: Purposive sample size

\begin{tabular}{|l|l|l|}
\hline S/N & BUILDINGS & LOCATION \\
\hline 1 & Nestoil Towers & Lagos \\
2 & Heritage Place & Lagos \\
3 & Kings Towers & Lagos \\
4 & Civic Center & Lagos \\
& Towers & \\
5 & Sterling House & Lagos \\
6 & KPMG Tower & Lagos \\
7 & UBA House & Lagos \\
8 & Union Bank & Lagos \\
\hline
\end{tabular}

An observation guide was used to rank biophilic design elements and their rate of occurrence in the selected office buildings. Table II shows the biophilic design forms used as a criterion to establish a pattern among the buildings selected. Some of the terms are further explained below:

[1] Pictorial illustration of link with nature: Views to the outdoors from interior through glazing.

[2] Concealed link with Nature: The sound of moving grasses can be heard around the site when outdoor.

[3] Irregular sensory reaction: Presence of native landscaping. [4] Heat and variation in air movement: Spaces are designed to allow airflow through skylight and operable glazing.

[6] Vital and dispersed light: Natural light from the courtyard, sunroom, and exterior refurbished windows

[7] Connection with Natural Systems. The outdoor sit out allows connection to native landscaping.

[8] Naturally occurring forms and patterns: the undulating form of the roofline.

[9] Material that mimic nature: The use of material finishes that mimic nature on the façade.

[14] Peril. Views around the site allows for easy sensing danger

The fig. 1 below shows the observation guide used with the various biophilic design patterns.

\section{Published By:}

Blue Eyes Intelligence Engineering

\& Sciences Publication

(C) Convriaht: All riahts reserved 


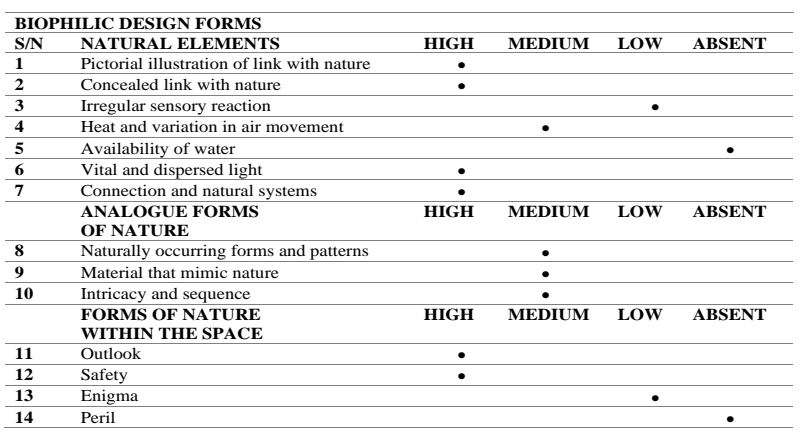

Fig.1. Observation guide

Table II shows mean score for the various biophilic design strategies that were assessed in the buildings.

Table- II: Mean score for biophilic design strategies: Descriptive analysis

\section{RESULTS}

\begin{tabular}{|c|c|c|c|}
\hline Design strategy & $\mathrm{N}$ & Mean & $\begin{array}{l}\text { Std. } \\
\text { Deviation }\end{array}$ \\
\hline $\begin{array}{l}\text { Daylighting is optimised in } \\
\text { the building }\end{array}$ & 58 & 4.48 & .599 \\
\hline Plants outside the building & 56 & 4.13 & .470 \\
\hline $\begin{array}{l}\text { Adequate openings that } \\
\text { enhance ventilation }\end{array}$ & 58 & 3.76 & .630 \\
\hline $\begin{array}{l}\text { Open view to the exterior } \\
\text { from my workstation }\end{array}$ & 57 & 3.46 & .781 \\
\hline $\begin{array}{l}\text { Presence of natural } \\
\text { materials like wood }\end{array}$ & 58 & 3.36 & .667 \\
\hline $\begin{array}{l}\text { There is adequate solar } \\
\text { shading provided against } \\
\text { light and heat for the } \\
\text { building }\end{array}$ & 58 & 3.19 & .805 \\
\hline Plants within the building & 58 & 3.03 & .878 \\
\hline $\begin{array}{l}\text { The placement of openings } \\
\text { encourages passive cooling }\end{array}$ & 54 & 2.85 & .684 \\
\hline $\begin{array}{l}\text { Space planning in the } \\
\text { building takes advantage of } \\
\text { the building's natural } \\
\text { thermal response }\end{array}$ & 55 & 2.75 & .751 \\
\hline $\begin{array}{l}\text { Open views of the plants } \\
\text { from your workstation }\end{array}$ & 56 & 2.70 & .658 \\
\hline Materials that mimic nature & 58 & 2.64 & .718 \\
\hline $\begin{array}{l}\text { The building doesn't get } \\
\text { uncomfortable when there is } \\
\text { no artificial energy supply }\end{array}$ & 58 & 2.48 & .843 \\
\hline $\begin{array}{l}\text { I have control over the } \\
\text { amount of natural light that } \\
\text { enters the space }\end{array}$ & 58 & 2.19 & .783 \\
\hline $\begin{array}{l}\text { Paintings/pictures of nature } \\
\text { in the building }\end{array}$ & 58 & 1.88 & .818 \\
\hline Presence of living walls & 56 & 1.66 & .483 \\
\hline Valid N & 58 & & \\
\hline
\end{tabular}

\section{CONCLUSION}

Descriptive statistics along with a measure of central tendency was used to summarize the features from the information gathered. The highest mean is approximately 4.48, which implies that most of the respondents concluded that daylighting is optimised in the respective selected buildings. The result of the extent to which biophilic design strategies are implemented in office buildings in the study area is analysed by ranking them in a descending order which signifies the level of agreement with these variables. Most respondents agree with the optimisation of daylight in these buildings, while implying that living walls are least present in the selected buildings.

With the ever-bearing tag of a developing country, there is a constant pressure to be relevant to the competitive business world, which has driven many companies into demanding overtime from their employees, while neglecting the well-being of their workers as well as creating a sustainable environment for them to thrive. Consequently, investing in people can recover lost productivity and increase profits, and at the same time foster lively, healthy and aesthetically pleasing workspaces.

\section{REFERENCES}

. Kellert, S. (2012). Birthright: People and Nature in the Modern World. New Haven: Yale University Press.

Kellert, S. H. (2013). Biophilic Design: The Theory, Science, and Practice of Bringing Buildings to Life. John Wiley \& Sons, Inc.

. Heerwagen, J. H. (2000, July/August). Do Green Buildings Enhance the Well Being of Workers? Yes. Environmental Design and Construction.

4. Kellert, S. (2018). Nature by Design: The Practice of Biophilic Design. Yale: Yale University Press.

5. Browning, W., Ryan, C., \& Clancy, J. (2014). 14 Patterns Of Biophilic Design: Improving Health \& Well-being in the Built Environment. New York: Terrapin Bright Green LLC J. Wang, "Fundamentals of erbium-doped fiber amplifiers arrays (Periodical style-Submitted for publication)," IEEE J. Quantum Electron., submitted for publication.

6. Browning, B. (2015). Healthier Workplaces, Happier Employees. Linking Theory + Practice.

7. Browning, W., Ryan, C., \& Clancy, J. (2014). 14 Patterns Of Biophilic Design: Improving Health \& Well-being in the Built Environment. New York: Terrapin Bright Green LLC.

8. Wilson, A. (2006, July 9). Biophilia in Practice: Buildings that Connect People with Nature. BuildingGreen, Inc.

. Mizell, M., \& Ritchie, R. (2018). Sustainable goals: Biophilic design, reduction of carbon footprint

10. Saner, E. (2012, April 03). Pot plants in the office: Good or bad? Retrieved from Guardian: www.guardian.co.uk/lifeandstyle/shortcuts/2012/apr/30/pot-plants-in-t he-office

11. Fenner, E. (2015). Beyond Sustainability: The benefits of biophilic design elements. The professional's choice.

2. Lerner, A., \& Stopka, M. (2016). The Financial Benefits of Biophilic Design in the Workplace. Chicago: Mist Environment.Cooper, C. (2015). HUMAN SPACES REPORT: Boiphiic Design in the Workplace. 